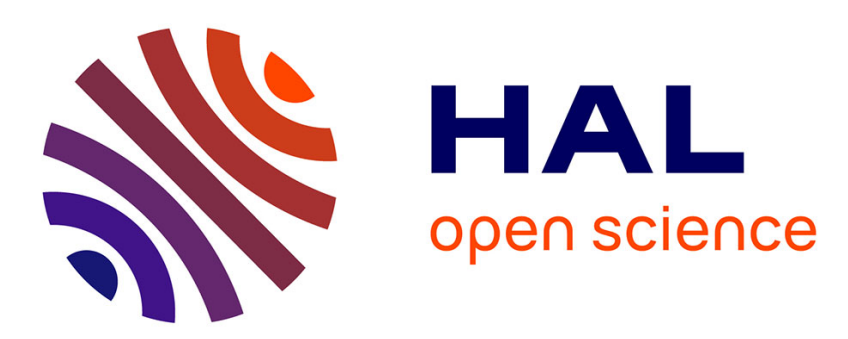

\title{
Isothermal crystallization kinetic modeling of poly(etherketoneketone) (PEKK) copolymer
}

T Choupin, Bruno Fayolle, Gilles Regnier, C. Paris, J Cinquin, B Brulé

\section{To cite this version:}

T Choupin, Bruno Fayolle, Gilles Regnier, C. Paris, J Cinquin, et al.. Isothermal crystallization kinetic modeling of poly(etherketoneketone) (PEKK) copolymer. Polymer, 2017, 111, pp.73-82. 10.1016/j.polymer.2017.01.033 . hal-01483789

\section{HAL Id: hal-01483789 \\ https://hal.science/hal-01483789}

Submitted on 6 Mar 2017

HAL is a multi-disciplinary open access archive for the deposit and dissemination of scientific research documents, whether they are published or not. The documents may come from teaching and research institutions in France or abroad, or from public or private research centers.
L'archive ouverte pluridisciplinaire HAL, est destinée au dépôt et à la diffusion de documents scientifiques de niveau recherche, publiés ou non, émanant des établissements d'enseignement et de recherche français ou étrangers, des laboratoires publics ou privés. 


\title{
Isothermal crystallization kinetic modeling of poly(etherketoneketone) (PEKK) copolymer
}

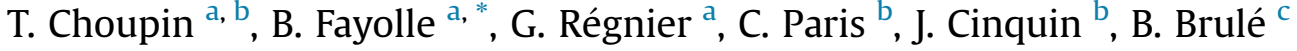 \\ a PIMM, ENSAM, CNRS, CNAM, 151 boulevard de l'Hôpital, 75013 Paris, France \\ b Departement of Composites Materials, Airbus Group Innovations, 12 rue Pasteur, 92150 Suresnes, France

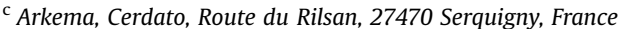

Keywords:

Thermoplastics

Poly(etherketoneketone)

Thermal analysis

Crystallization kinetic

Crystallization induction time

X-ray diffraction

\begin{abstract}
A B S T R A C T
Isothermal melt and cold crystallizations of a poly(etherketoneketone) (PEKK) copolymer prepared from diphenyl ether (DPE), terephthalic acid (T) and isophthalic acid (I) with a T/I ratio of 60/40 have been investigated by differential scanning calorimetry, wide-angle X-ray scattering and polarized optical microscopy. For the first time, the two-stage overall crystallization kinetics of PEKK taking into account effects of nucleation and crystal growth has been identified by using a modified Hillier type model. The primary crystallization stage is found to be an instantaneous two dimensional nucleation growth with an Avrami exponent of 2 whereas the secondary stage is found to be an instantaneous one dimensional nucleation growth with an Avrami exponent of 1 . The evolution of the crystallization kinetic constants for two-stage crystallizations has been modeled according to the Hoffman and Lauritzen growth theory. Due to low crystallization kinetics, a crystallization induction time has been added to obtain a good fit with experimental data. Based on this modeling, Time-Temperature-Transformation (TTT) diagrams of the relative volume crystallinity have been established for the overall crystallization mechanism and also for the separated primary and secondary crystallization mechanisms providing an original crystallization mapping of the material.
\end{abstract}

\section{Introduction}

High performance thermoplastic poly(aryletherketone) (PAEK) matrices are increasingly used in aeronautics for composite structural parts. They have high temperature performances, good impact properties, high chemical and oxidation resistance and as all thermoplastics, they are recyclable and weldable. They are especially suitable for automated composite fiber tape placement and for out of autoclave consolidation. Those two features would help increase the aircraft production rate which is currently a major issue for aircraft manufacturers.

PAEKs differ from each other in the ratio of ether/ketone. PEEK has been the most studied since the 1990s [1-8] because of its high temperature performances, and its chemical and oxidation resistance. However, it has a high melting temperature which makes its processing difficult. PEKK copolymers have been studied by few authors in the 1990s [9-14] and they have not aroused great

\footnotetext{
* Corresponding author.

E-mail address: bruno.fayolle@ensam.eu (B. Fayolle).
}

interest until recently [15-18]. They are prepared form diphenyl ether (DPE), terephathlic acid (T) with para phenyl links and isophthalic acid (I) with meta phenyl links and differ from each other with their $\mathrm{T} / \mathrm{I}$ ratios. Their melting temperatures $\left(\mathrm{T}_{\mathrm{m}}\right)$ decrease with the $\mathrm{T} / \mathrm{I}$ ratio without changing significantly their glass transition temperature $\left(\mathrm{T}_{g}\right)$ [9]. This is due to a lowering of the macromolecular chains regularity with the T/I ratio which decreases the crystalline phase compactness [9]. PEKK 60/40 has a $\mathrm{T}_{\mathrm{g}}$ about $156{ }^{\circ} \mathrm{C}$ and a $\mathrm{T}_{\mathrm{m}}$ about $300{ }^{\circ} \mathrm{C}$ [18], which is lower than the one for PEEK (around $340{ }^{\circ} \mathrm{C}[2]$ ). This is quite interesting for processing regarding part manufacturing costs and possible degradation at high temperature. At last, PEKK 60/40 crystallizes less and slower than PEEK because ketone linkages are stiffer than ether linkages. The maximum crystallinity varies between $22 \%$ and $27 \%$ and it does not crystallize for cooling rates above $10^{\circ} \mathrm{C} \cdot \mathrm{min}^{-1}$ [18].

Isothermal crystallization mechanisms of PEKK 60/40 have been studied by Gardner et al. [9] and Cortés et al. [18]. After annealing, they observed an additional endotherm during the melting which occurs about $10^{\circ} \mathrm{C}$ above the annealing temperature. Such behavior has also been observed for PEEK $[2,4,19]$ and other semi-crystalline polymers as poly(ethyleneterephthalate) [20-22] and is called the 
double-melting behavior. This additional endotherm is attributed to the melting of a secondary crystallization associated to the growth of an interlamellar crystalline structure within lamellae [23]. This subsidiary crystallization appears after long annealing or slow cooling rates. Gardner et al. [9] also studied the PEKK 60/40 isothermal crystallization kinetics with a peak-time method (time for which the crystallization exothermic peak is maximum) [9] but did not use a crystallization kinetic model taking into account the two-stage crystallization.

Different studies have been made to incorporate the two-stage crystallization into the crystallization kinetic modeling of polymers, the two most relevant reported are the Velisaris Seferis [5] and the Hillier models [23]. The former postulates that two Avrami type crystallization processes [24] occur in parallel independently whereas the second assumes that a primary Avrami type crystallization process occurs followed by a first order crystallization process which grows from the primary crystallization. Hsiao et al. [12] investigated the isothermal crystallization kinetics of a PEKK 70/30 with a modified Hillier model which postulates that the secondary crystallization is not necessarily a first order process and compared it to the Velisaris Seferis model. They concluded that the modified Hillier model has a better physical meaning than the Velisaris Seferis one because it is more suitable to describe the growth of a second crystalline structure within lamellae. In this model, the primary crystallization is expressed by an Avrami equation:

$\alpha_{1}(t)=1-\exp \left(-K_{1} t^{n_{1}}\right)$

where $\alpha_{1}(t)$ is the relative volume fraction crystallinity at time $t, w_{1}$ is the weight factor between primary and secondary crystallizations, $K_{1}$ is the crystallization rate constant both depending on the annealing temperature and $\mathrm{n}_{1}$ the Avrami exponent depending on the nucleation and the growth geometry, for the first mechanism. The secondary crystallization process which occurs once a volume element has been included in the lamellae at time $\theta$ is expressed by an Avrami equation:

$\alpha_{2}(t)=\int_{0}^{t} \alpha_{1}(\theta) \times \frac{d}{d t}\left(\alpha_{2}(t-\theta)\right) d \theta$

where $\alpha_{2}(t-\theta)$ is the relative volume fraction crystallinity at time t, w2 is the weight factor, $K_{2}$ is the crystallization rate constant both depending on the annealing temperature and $n_{2}$ the Avrami exponent depending on the nucleation and the growth geometry, for the second mechanism. The Avrami exponent $\mathrm{n}_{2}$ is not necessarily equal to 1 according to Hsiao et al. [12]. The total crystallinity at time $t$ arising from those two consecutive crystallization processes becomes:

$\alpha(t)=w_{1} \alpha_{1}(t)+w_{2} \alpha_{2}(t)$

From Equations (1)-(3):

$$
\begin{aligned}
\alpha(t)= & w_{1}\left[1-\exp \left(-K_{1} t^{n_{1}}\right)\right]+w_{2} K_{2} n_{2} \int_{0}^{t}\left[1-\exp \left(-K_{1} \theta^{n_{1}}\right)\right. \\
& \times](t-\theta)^{n_{2}-1} \exp \left[-K_{2}(t-\theta)^{n_{2}}\right] d \theta
\end{aligned}
$$

where $\mathrm{w}_{1}+\mathrm{w}_{2}=1$, indicating that the relative crystallinity at infinite time is unity which corresponds to the Avrami model hypotheses [24]. Values of weight factors provide the relative importance between both crystallizations. It can be noticed that
Equation (4) differs from Hsiao et al. [12] model which could be due to a misprint in their article for the derivative of the secondary crystallization in Equation (2).

This paper aimed to investigate the isothermal crystallization kinetics of PEKK 60/40 with a modified Hillier model for crystallization from the melt and cold crystallization to predict precisely the crystallinity evolution according to processing cycles. Basing on experimental data, parameters associated to the modified Hillier model will be assessed carefully and their physical meanings will be discussed. Finally, Time-Temperature-Transformation (TTT) diagrams of the relative volume crystallinity will be built from the overall crystallization modeling.

\section{Experimental}

\subsection{Material and preparation}

PEKK used in this study was provided by Arkema referenced as PEKK 6002. It was prepared from diphenyl ether (DPE), terephthalic acid (T) with para phenyl links and isophthalic acid (I) with meta phenyl links with a T/I ratio of 60/40 (Fig. 1). PEKK 60/40 has a weight-average molecular weight (Mw) of about $60000 \mathrm{~g} \mathrm{~mol}^{-1}$. PEKK samples were supplied amorphous with no crystalline traces measured by DSC and WAXS. The glass transition and melting temperatures were respectively measured about $155^{\circ} \mathrm{C}$ and $292^{\circ} \mathrm{C}$ by DSC with a heating stage at $10^{\circ} \mathrm{C} / \mathrm{min}$.

\subsection{Differential scanning calorimetry}

Isothermal crystallization analyses were carried out in a TA Instruments Q2000 on granules of about 7-8 mg. For cold and melt crystallization, all specimens were first heated at $10^{\circ} \mathrm{C} . \mathrm{min}^{-1}$ from room temperature to $360{ }^{\circ} \mathrm{C}$ during $5 \mathrm{~min}$. This temperature is above the PEKK 60/40 equilibrium melting temperature $\left(\mathrm{T}_{\mathrm{mo}}=340^{\circ} \mathrm{C}\right.$ [9]) to erase the thermal history and obtain a fully amorphous polymer. For crystallization from the melt, specimens were then cooled at $40{ }^{\circ} \mathrm{C} \cdot \mathrm{min}^{-1}$ to annealing temperatures during $120 \mathrm{~min}$ and finally cooled to room temperature at $40^{\circ} \mathrm{C} \cdot \mathrm{min}^{-1}$. During the cooling steps, the polymer does not have enough time to crystallize and the annealing time is long enough to allow the polymer to fully crystallize. For cold crystallization, the polymer is cooled at $40{ }^{\circ} \mathrm{C} \cdot \mathrm{min}^{-1}$ to room temperature and then heated at $80{ }^{\circ} \mathrm{C} \cdot \mathrm{min}^{-1}$ to the isothermal temperature during $120 \mathrm{~min}$ and finally cooled at $40{ }^{\circ} \mathrm{C} \cdot \mathrm{min}^{-1}$ to room temperature. For all specimens after crystallization, a heat scan at $10^{\circ} \mathrm{C} \cdot \mathrm{min}^{-1}$ to $360^{\circ} \mathrm{C}$ was carried out to measure the glass transition, the melting temperature and the melting enthalpy induced by the crystallization cycle.

\subsection{Wide-angle $X$-ray diffraction}

The X-ray data were collected by performing wide angle X-ray scattering (WAXS) patterns at room temperature on samples with a thickness of $2 \mathrm{~mm}$ thanks to the SAXS/WAXS system from Xenocs. The apparatus consists of an X-ray source using a copper anode $\mathrm{K}_{\alpha}$ radiation with a wavelength of a 1.54 A delivering a parallel beam. The X-ray patterns were recorded with a MAR300 2D detector

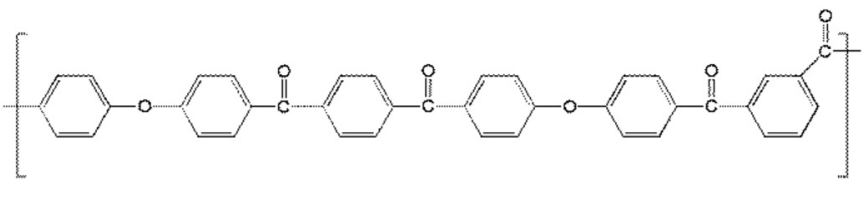

Fig. 1. Chemical structure of PEKK copolymers. 
piloted with the MAR300 software. The sample to detector distance was $168 \mathrm{~mm}$. Silver behenate standard reference material was used for sample-to-detector distance calibration. The exposure time was $15 \mathrm{~h}$. The 2D patterns were treated using Fit2D software developed by the European Synchrotron (ESRF). The 2D X-ray diffraction patterns were integrated along the azimuthal direction from isotropic samples.

\subsection{Optical microscopy}

The optical microscope used was a polarizing Nikon Eclipse LV100 model equipped with a Nikon DS Digital Sight DS-Fi1 camera and a hot stage Linkam LTS-420. Observations were carried out with an ocular lens of $30 \times$ on PEKK film with a thickness of $5 \mu \mathrm{m}$ prepared with a Leica RM-2235 microtom. Films were first heated at $10{ }^{\circ} \mathrm{C}$. $\mathrm{min}^{-1}$ from room temperature to $360{ }^{\circ} \mathrm{C}$ during $5 \mathrm{~min}$ to erase the thermal history of the specimen and then cooled down at $40{ }^{\circ} \mathrm{C} . \mathrm{min}^{-1}$ to $270{ }^{\circ} \mathrm{C}$ during $2 \mathrm{~h}$. This annealing temperature corresponds to a low supercooling i.e. to a low nucleation rate allowing the formation of large spherulites.

\section{Results and discussion}

\subsection{Crystalline morphology}

WAXS measurements have been carried out on a PEKK 60/40 sample crystallized from the melt and from the glassy state at $230{ }^{\circ} \mathrm{C}$ during $2 \mathrm{~h}$ (Fig. 2). It has been observed for crystallization from the melting state a diffraction pattern with the (110) peak at $2 \theta=18.7^{\circ}$, the (111) peak at $2 \theta=20.6^{\circ}$ and the (200) peak at $2 \theta=22.7^{\circ}$. This pattern is similar to what was reported in the literature for other PAEKs $[1,2,9,25]$ and has been indexed by a twochain orthorhombic unit cell with dimension $\mathrm{a}=0.767 \mathrm{~nm}$, $\mathrm{b}=0.606 \mathrm{~nm}$ and chain axis $\mathrm{c}=1.008 \mathrm{~nm}[10]$. An additional pattern with the $(020)$ peak at $2 \theta=16^{\circ}$ has been observed which has already been reported by DuPont and ICI research group

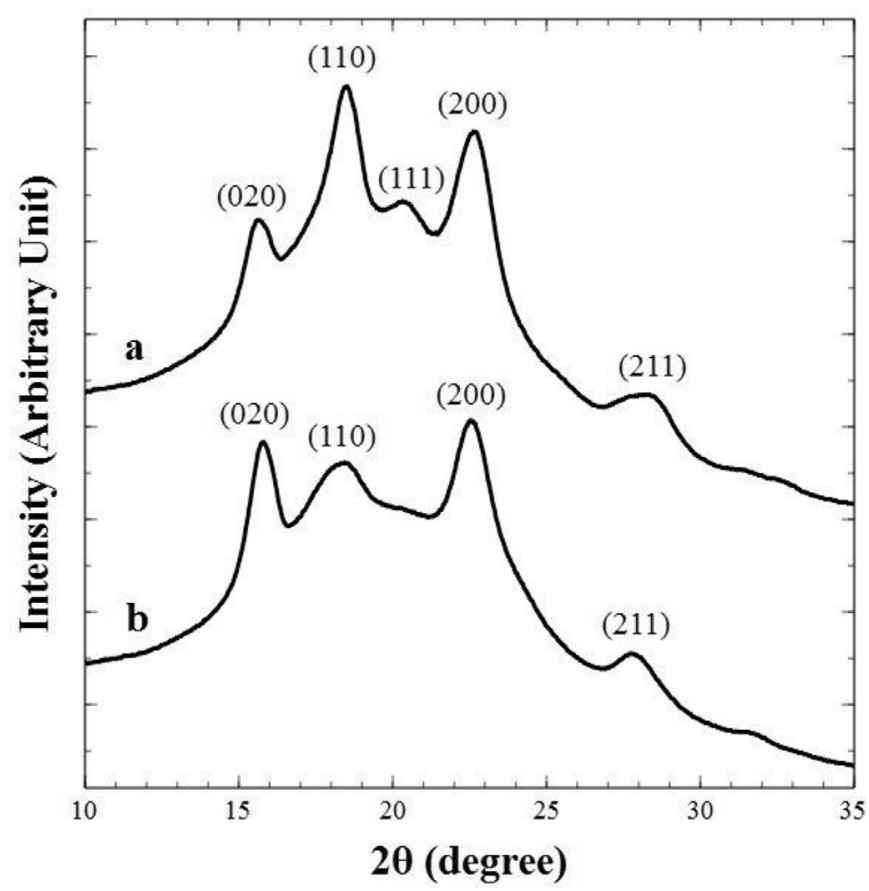

Fig. 2. X-ray diffraction scans of PEKK $60 / 40$ crystallized at $230{ }^{\circ} \mathrm{C}$ during $2 \mathrm{~h}$ from the melting state (a) and from the glassy state (b).
[10,11,26-28] and Blundell et al. [13] for PEKK. It has been identified by a second morphology (form II) with a one or two-chain orthorhombic lattice depending on the authors. This subsidiary morphology would appear for high chain stiffness and low molecular mobility. PEKK copolymers have a high ratio of ketone linkages which increases the stiffness of the molecule and allow the apparition of the form II. In fact, ketone linkages have high rotational conformation energy barriers which enhance chain stiffness.

For PEKK 60/40 crystallized from the glassy state, a more important (020) peak has been observed compared to crystallization from the melting state and the (111) peak is non-existent. This is consistent with the fact that cold crystallization induces low chain mobility enhancing the growth of the form II. The disappearing of the (111) peak highlights that PEKK 60/40 crystallized from the glassy state presents only pure form II.

\subsection{Nucleation and growth}

Fig. 3 shows the crystal growth of a PEKK 60/40 sample crystallized from the melt at $270{ }^{\circ} \mathrm{C}$ during $20 \mathrm{~min}$ (Fig. 3a), $30 \mathrm{~min}$ (Fig. 3b) and 40 min (Fig. 3c). Radial growths of crystalline entities similar to spherulites were observed. During the first step of crystallization, the crystalline entities grow independently to each other with the same size until impingement which is typical to an instantaneous nucleation. The initial number of potential nuclei $\mathrm{N}_{0}$ has been calculated about $0.0069 \mu \mathrm{m}^{-2}$. It is equal to the number of nuclei at the early beginning of the crystallization divided by the area containing the nuclei which have been both measured with an image processing program. At the end of the crystallization process, the crystalline entities diameters have been measured from $18 \mu \mathrm{m}$ to $33 \mu \mathrm{m}$.

The evolution of the radius of a spherulite during the crystallization process as a function of time at $270{ }^{\circ} \mathrm{C}$ from the melting state has been followed in Fig. 4. In order to assess the crystalline growth rate, the spherulite has been chosen to be the most far as possible from the others to collect enough data before impingement. It can be observed three different steps during the crystallization process. The first step is related to the crystallization initiation where the spherulite studied was first observed after 8 min of crystallization with a radius of $2 \mu \mathrm{m}$. This time depends on the device resolution. After this initiation step, the spherulite grows constantly until it impinges on another spherulite. The growth rate is independent of the size of the spherulite and calculated from the slope of the line by $\mathrm{G}=\mathrm{dr} / \mathrm{dt}$. The growth rate of spherulites at $270{ }^{\circ} \mathrm{C}$ from the melt has been measured about $0.2 \mu \mathrm{m} \mathrm{min}{ }^{-1}$. At the end of the crystallization growth, the radius has been observed about $16.5 \mu \mathrm{m}$. Those results will be compared later with the following DSC study.

\subsection{Thermal analysis methods}

Isothermal DSC scans of PEKK 60/40 samples at $210{ }^{\circ} \mathrm{C}$ and $230{ }^{\circ} \mathrm{C}$ cooled at $40^{\circ} \mathrm{C} . \mathrm{min}^{-1}$ from the melt are reported in Fig. 5 a. It can be witnessed that the beginning of the crystallization exothermic peaks are truncated corresponding to a gap between the beginning of the crystallization peak and the baseline (double arrow in Fig. 5a). This phenomenon is due to the instrumental thermal inertia switching from the cooling to the isothermal step. It can be observed that this gap is more important for isothermal at $230^{\circ} \mathrm{C}$ than $210^{\circ} \mathrm{C}$ due to higher crystallization kinetics at $230^{\circ} \mathrm{C}$. Therefore, the beginning of the crystallization peak has been extrapolated until the base line with a linear curve (dashed line in Fig. 5b) to take into account the overall crystallization process.

As the crystallization kinetics of PEKK 60/40 is relatively low compared to most of semi-crystalline polymers, polyolefines for instance [29], it can be detected a delay between the beginning of 

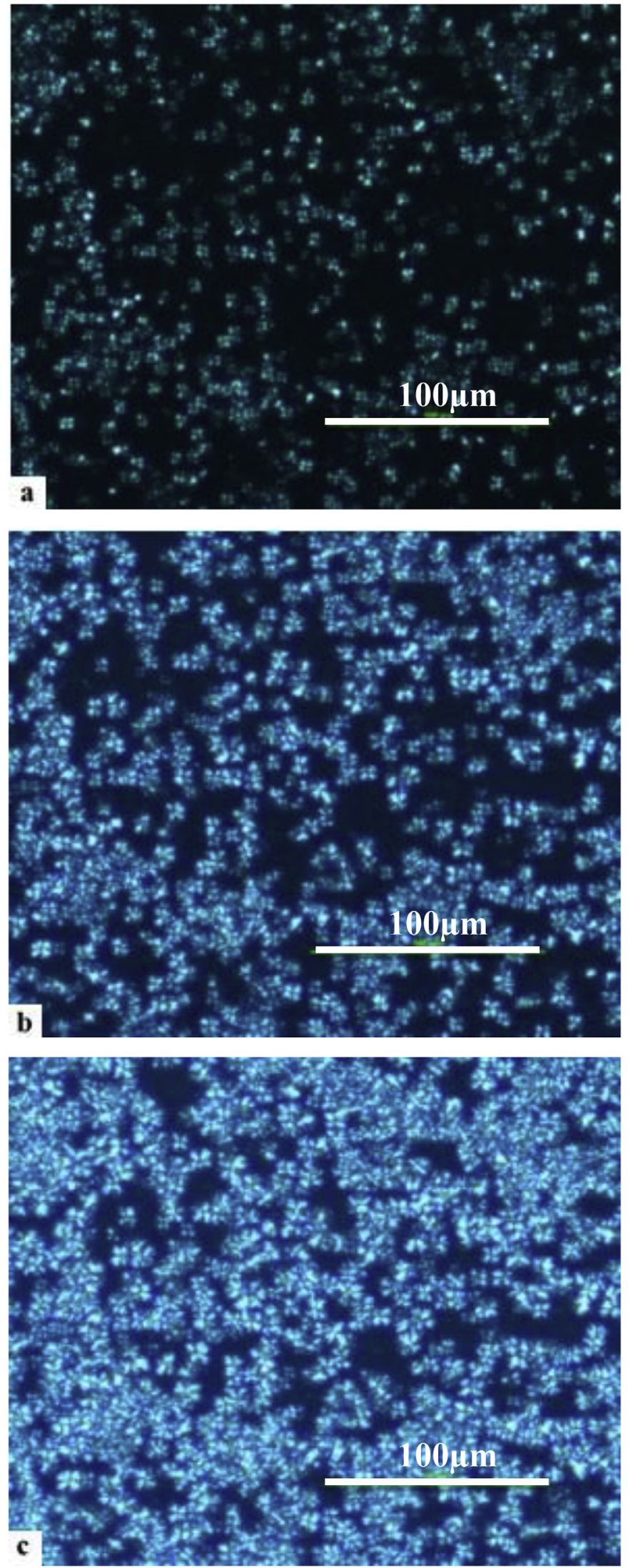

Fig. 3. Micrographs of PEKK $60 / 40$ crystallized from the melt at $270{ }^{\circ} \mathrm{C}$ during $20 \mathrm{~min}$ (a), 30min (b) and 40min (c).

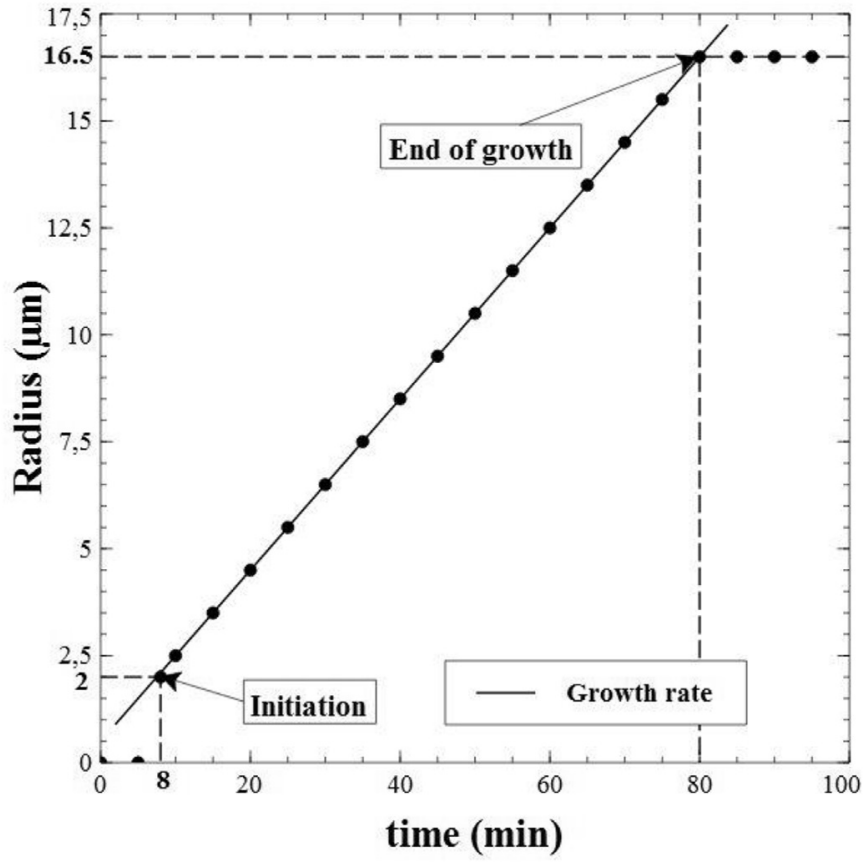

Fig. 4. Spherulite radius vs time during crystallization at $270{ }^{\circ} \mathrm{C}$ from the melting state.

the isotherm and the crystallization process. This delay has also been observed for other polymers with low crystallization kinetics and modeled as a crystallization induction time $\left(t_{i}\right)[21,30]$. It corresponds to the time to reach a steady state of nucleation i.e. the time to reach enough critical nuclei in the bulk to initiate crystallization. Indeed, the increase in number of critical nuclei which leads into the steady state linear is initially slow [31]. In this work, the induction time $t_{i}$ has been defined by the intersection of the baseline and the extrapolation line of the crystallization peak beginning (Fig. 5b). Without taking into account this crystallization induction time, the multilinear regression on Hillier's model coefficients was not able to give a very good fit of experimental data.

\subsection{Isothermal crystallization kinetic modeling}

For each isothermal crystallization, the relative volume fraction of crystallinity $\alpha(\mathrm{t})$ has been calculated by dividing the partial area at time $t$ by the overall area of the extrapolated crystallization exothermic peak (Fig. 6) and its double logarithm has been plotted in Fig. 7. The induction time as defined previously has been taken into account for the plots of $\alpha$. Straight line have been observed for the double logarithm plot in Fig. 7 during the beginning of the crystallization which is consistent with the Avrami theory. For every crystallization, the slopes of the lines corresponding to the Avrami exponent have been measured about $2.05 \pm 0.01$ in Fig. 7 (dashed lines). The corresponding Avrami model (Equation (1)) has been plotted in Fig. 6 (dashed lines) with an Avrami exponent $\mathrm{n}_{1}$ fixed by 2 . It can be observed that the Avrami model fits well with experiments for relative crystallinity below 0.6. According to the Avrami theory, a value of 2 for the Avrami exponent would be associated either to a two dimensional crystallization growth with an instantaneous nucleation or to a one dimensional crystallization growth with a sporadic nucleation. Since the microscopic study has shown previously that the nucleation process is instantaneous (Fig. 3), it can be assumed that the first crystallization mechanism would be a two dimensional disk-like crystallization. However, this assumption does not seem consistent with the microscopic 

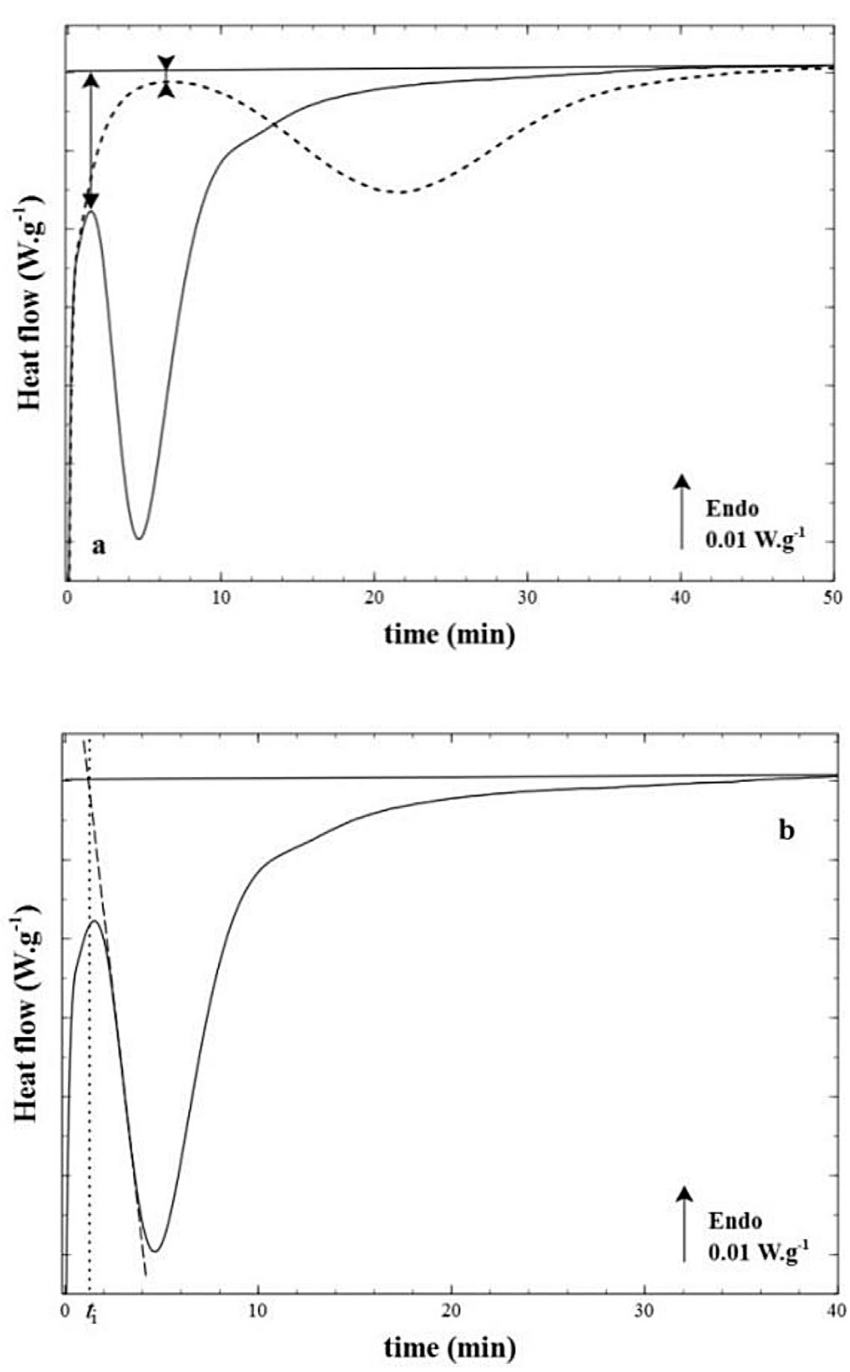

Fig. 5. DSC thermograms of PEKK $60 / 40$ crystallized from the melt during isothermal crystallization at $230{ }^{\circ} \mathrm{C}$ (solid line) and $210{ }^{\circ} \mathrm{C}$ (dashed line) (a) and the extrapolated line of the crystallization peak beginning (dashed line) with the crystallization induction time $\mathrm{t}_{\mathrm{i}}$ (dotted line) at $230^{\circ} \mathrm{C}(\mathrm{b})$.

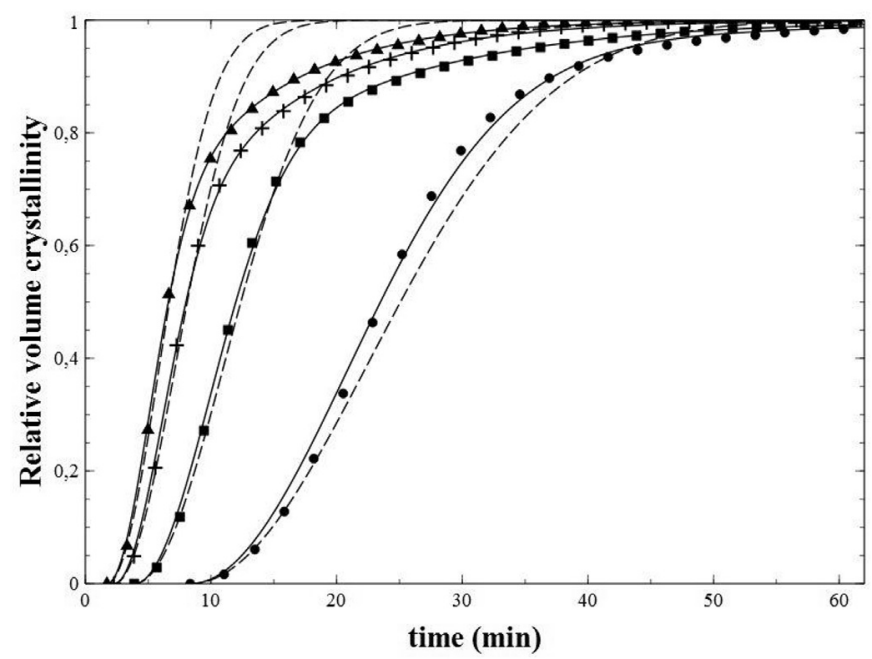

Fig. 6. Relative volume fraction crystallinity $\alpha(\mathrm{t})$ vs time $\left(\bullet, 200{ }^{\circ} \mathrm{C} ; \mathbf{\square}, 210^{\circ} \mathrm{C}\right.$; $220^{\circ} \mathrm{C} ; \boldsymbol{\Delta}, 230^{\circ} \mathrm{C}$ ), the Avrami model (dashed curves) and the Hillier model (solid curves) plots for PEKK 60/40 isothermal crystallization from the melt.

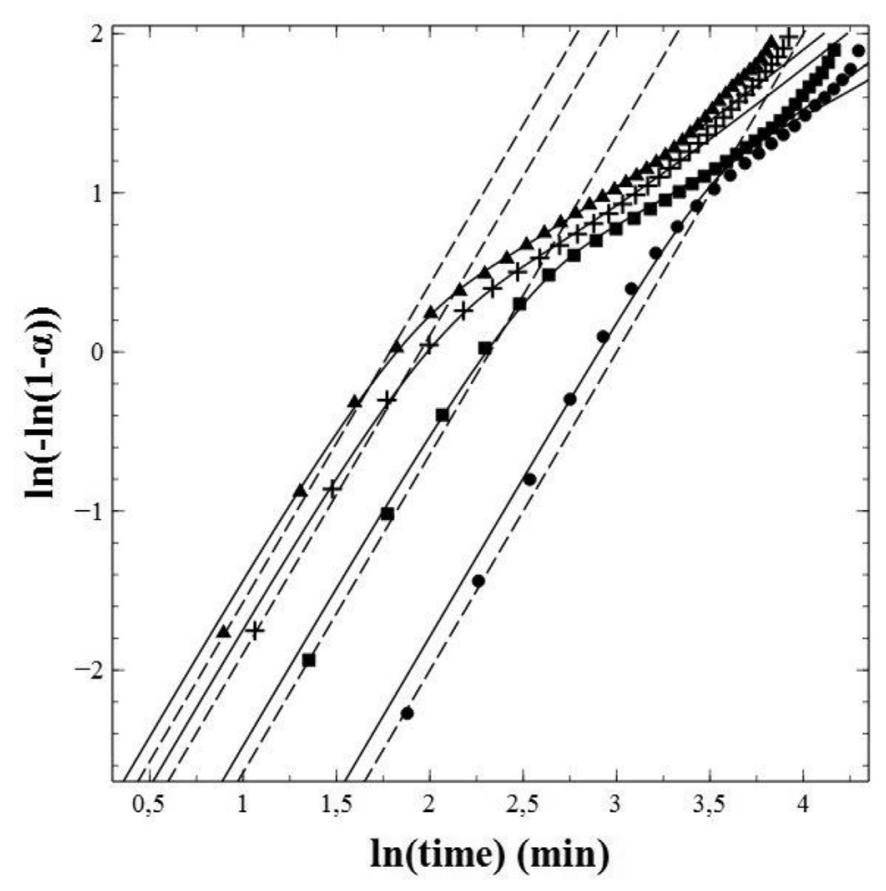

Fig. 7. Double logarithm vs $\ln ($ time $)\left(\bullet, 200^{\circ} \mathrm{C} ; \boldsymbol{\square}, 210^{\circ} \mathrm{C} ;+, 220^{\circ} \mathrm{C} ; \boldsymbol{\Delta}, 230^{\circ} \mathrm{C}\right)$, the Avrami model (dashed curves) and the Hillier model (solid curves) plots for PEKK 60/ 40 isothermal crystallization from the melt.

observations where growing crystalline entities behave like spherulites. This phenomenon has already been observed for Poly(ethylene Oxide) by Banks and Sharples [32] and they concluded that the Avrami exponent is not necessarily satisfactory to provide information on crystallization mechanisms [33].

For values of relative crystallinity above 0.6 , crystallization kinetics become slower than the Avrami model which corresponds to a bending of the double logarithm plots in Fig. 7. This phenomenon is typical of the formation of a secondary crystallization process within the primary crystallization with a slower crystallization kinetic $[5,12]$. The modified Hillier model previously presented (Equation (4)) has been used to take into account this secondary crystallization and fit with experiments during the overall crystallization process. The best fit of the Hillier model determined with a multi linear regression fitting has been found for a secondary crystallization Avrami exponent $\mathrm{n}_{2}=1$. It is associated to a one dimensional crystallization growth with an instantaneous nucleation. This result was also reported for polymethylene by Hillier [23] attributed to a first-order crystallization law within the crystalline lamellae. The same approach has been done for cold crystallization and same Avrami exponents have been found. Values of $\mathrm{n}_{1}$ and $\mathrm{n}_{2}$ are lower than those reported for PEEK [4] and PEKK 70/ 30 [12] which can be explained by a different nucleation and growth process. Results of the fitting of the modified Hillier model with $\mathrm{n}_{1}=2$ and $\mathrm{n}_{2}=1$ for $\mathrm{K}_{1}, \mathrm{~K}_{2}$ and $\mathrm{w}_{1}$ are discussed below.

Following the general approach reported in literature for nucleation and crystallization growth, crystallization rate constants $\left(\mathrm{K}_{1}\right.$ and $\left.\mathrm{K}_{2}\right)$ can be expressed as a function of the initial number of potential nuclei $\left(\mathrm{N}_{0}\right)$ and the crystal growth rate $(\mathrm{G})$ depending on the dimensionality of crystallization and the nucleation mode. For the primary crystallization which has been shown to have a two dimensional crystallization growth with an instantaneous nucleation, the crystallization rate constant can be written: 
$K_{1}=\pi N_{01} G_{1}^{2}$

with $\mathrm{N}_{01}$ the initial number of potential nuclei and $\mathrm{G}_{1}$ the crystallization growth rate for the primary crystallization.

For the secondary crystallization which has been shown to have a one dimensional crystallization growth with an instantaneous nucleation, the crystallization rate constant can be written:

$K_{2}=N_{02} G_{2}$

with $\mathrm{N}_{02}$ the initial number of potential nuclei and $\mathrm{G}_{2}$ the crystallization growth rate for the secondary crystallization.

According to the Hoffmann and Lauritzen theory [34-36], the crystal growth can be expressed by:

$G_{i}(T)=G_{0 i} \exp \left(-\frac{U^{*}}{R\left(T-T_{\infty}\right)}\right) \exp \left(-\frac{K_{g i}}{T \Delta T f}\right)$

where $\mathrm{G}_{0 \mathrm{i}}$ is a pre-exponential factor independent of the temperature. The first exponential term contains the contribution of the diffusion process to the growth rate, where $U^{*}$ is the activation energy of the molecular transferring through the melt crystal interface $\left(\mathrm{U}^{*}=6300 \mathrm{~J} \mathrm{~mol}^{-1}[35]\right), \mathrm{T}_{\infty}$ is the temperature below which diffusion stops $\left(T_{\infty}=T_{g}-30 \mathrm{~K}\right)$ and $\mathrm{R}$ is the gas constant. The second exponential term is the contribution of the nucleation process, where Kgi is the activation energy of nucleation for a crystal with a critical size, $\Delta \mathrm{T}$ is the degree of supercooling $(\Delta \mathrm{T}=\mathrm{Tm} 0-\mathrm{T})$ with $\mathrm{Tm} 0=340 \mathrm{~K}[9]$ and $\mathrm{f}$ is a correction coefficient for the temperature dependence of the melting enthalpy $(f=2 T)$ $(\operatorname{Tm} 0+\mathrm{T})$ ). The index i for $\mathrm{G}_{\mathrm{i}}, \mathrm{G}_{0 \mathrm{i}}$ and $\mathrm{K}_{\mathrm{gi}}$ is equal to 1 for primary crystallization and 2 for secondary crystallization.

Finally, the primary crystallization rate constant can be written:

$K_{1}(T)=K_{01} \exp \left(-\frac{2 U^{*}}{R\left(T-T_{\infty}\right)}\right) \exp \left(-\frac{2 K_{g 1}}{T \Delta T f}\right)$

And the secondary crystallization rate constant can be written:

$K_{2}(T)=K_{02} \exp \left(-\frac{U^{*}}{R\left(T-T_{\infty}\right)}\right) \exp \left(-\frac{K_{g 2}}{T \Delta T f}\right)$

with the pre-exponential factors independent of temperature $K_{01}=\pi N_{01} G_{01}^{2}$ and $K_{02}=N_{02} G_{02}$.

$\mathrm{K}_{1}$ and $\mathrm{K}_{2}$ have been plotted respectively in Fig. 8a and Fig. 8b and fitted with respectively Equations (8) and (9) for crystallization from the melt and cold crystallization. As expected, we observed that both plots have typical bell shapes regarding the Hoffman and Lauritzen growth theory [35]. Crystallization kinetics are the most important around $230{ }^{\circ} \mathrm{C}$ and very low close to the $\mathrm{T}_{\mathrm{g}}$ and $\mathrm{T}_{\mathrm{m}}$ corresponding to low diffusion and nucleation kinetics respectively. Interestingly, it appears that primary crystallization rate constants for cold crystallization are higher than those for crystallization from the melt. However, it is the opposite for secondary crystallization rate constants. This has been attributed to a lower final degree of crystallinity (i.e. $\Delta \mathrm{H}_{\mathrm{c}}$ ) for cold crystallization than crystallization from the melt (Table 1). Values of $\mathrm{K}_{\mathrm{gi}}$ are similar to those reported in the literature for other PAEKs [37,38]. It is noteworthy that crystallization rate constants $\left(\mathrm{K}_{1}\right.$ and $\left.\mathrm{K}_{2}\right)$ for isothermal crystallization at $200{ }^{\circ} \mathrm{C}, 260^{\circ} \mathrm{C}$ and $270{ }^{\circ} \mathrm{C}$ (unfilled marks in Fig. 8) have not been taken into account for the fitting because of a lower final crystallinity compared for the other temperatures (Table 1) involving higher rate constants. Indeed, for those temperatures, crystallization kinetics are very low which makes difficult the integration of the end of the DSC crystallization peak which truncates the overall area of the crystallization peak and underestimates the
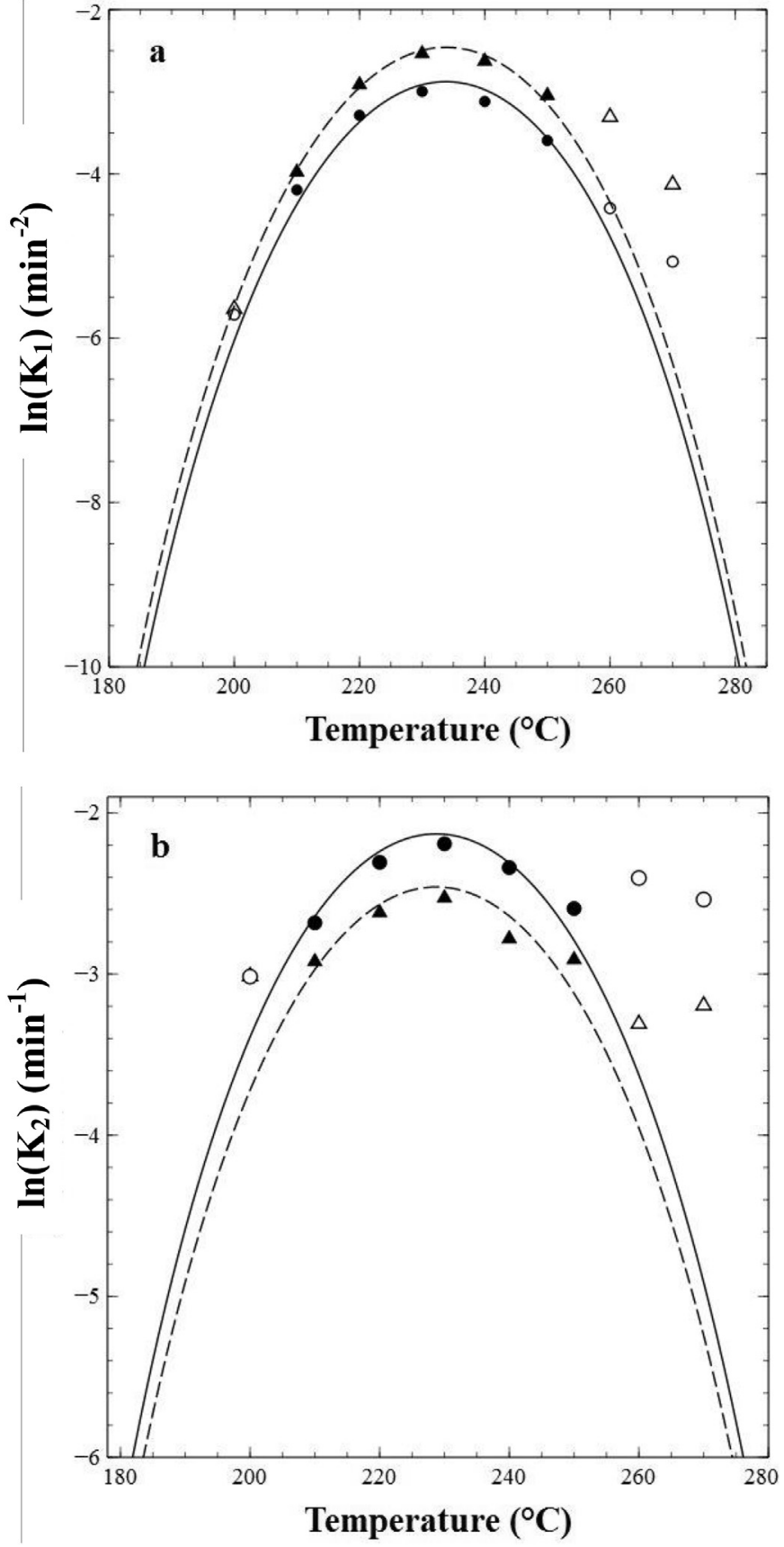

Fig. 8. Logarithmic plot of the primary (a) and the secondary crystallization (b) rate constants vs temperature for isothermal crystallization from the melt $(\mathbf{0})$ and cold crystallization ( $\mathbf{\Delta}$ ) with the Hoffman and Lauritzen model fitting with a solid line for crystallization from the melt and dashed line for cold crystallization. Unfilled markers have not been taken into account for the fitting.

crystallization enthalpy.

Since, the crystallization rate constant $K_{1}$ is linked to $G_{1}$ with Equation (5), we propose to crosscheck $K_{1}$ value with the previous microscopic study assuming that the spherolite growth rate is equal to the crystalline lamellae growth rate. Thanks to this study, the growth rate $G$ at $270{ }^{\circ} \mathrm{C}$ from the melt and the initial number of potential nuclei $\mathrm{N}_{0}$ were measured about $0.2 \mu \mathrm{m} \min ^{-1}$ and $0.0069 \mu \mathrm{m}^{-2}$ respectively. By assuming that the growth rate is mainly associated to the primary crystallization process, the crystallization rate constant $\ln \left(\mathrm{K}_{1}\right)$ were calculated about $-7.04 \mathrm{~min}^{-1}$ 
Table 1

Comparison of the isothermal crystallization enthalpy $\Delta \mathrm{H}_{\mathrm{c}}$ for crystallization from the melt and cold crystallization.

\begin{tabular}{lll}
\hline $\begin{array}{l}\text { Temperature } \\
\left({ }^{\circ} \mathrm{C}\right)\end{array}$ & $\begin{array}{l}\Delta \mathrm{H}_{\mathrm{c}} \text { melt } \\
\left(\mathrm{J} \cdot \mathrm{g}^{-1}\right)\end{array}$ & $\begin{array}{l}\Delta \mathrm{H}_{\mathrm{c}} \text { cold } \\
\left(\mathrm{J} \cdot \mathrm{g}^{-1}\right)\end{array}$ \\
\hline 200 & 18.4 & 17.1 \\
210 & 21.5 & 20.2 \\
220 & 23.3 & 19.6 \\
230 & 23.2 & 21 \\
240 & 23.9 & 21 \\
250 & 20 & 20.1 \\
260 & 17.1 & 16 \\
270 & 15.8 & 15.7 \\
\hline
\end{tabular}

with Equation (5). This value is consistent with the $\ln \left(\mathrm{K}_{1}\right)$ value calculated with the Hillier model at $270{ }^{\circ} \mathrm{C}$ from the melt about $-6.8 \mathrm{~min}^{-1}$ (Fig. 8). It is noteworthy that the $\ln \left(\mathrm{K}_{1}\right)$ value calculated with the microscope study is slightly lower than the one calculated with the Hillier model and fits better with the Hoffman and Lauritzen modeling (solid line in Fig. 8). In fact, the issue of the truncation of the end of the DSC crystallization peak related previously (Table 1 ) does not exist for the spherulites growth method. However, this method needs high temperature crystallizations allowing the growth of large spherulites to be able to measure accurately their size during crystallization which becomes difficult for temperatures below $260^{\circ} \mathrm{C}$.

The primary crystallization weight factor $\left(w_{1}\right)$ for crystallization from the melt and cold crystallization has been plotted as a function of temperature in Fig. 9. It has been modeled with a linear equation:

$w_{1}(T)=a_{1} T+b_{1}$

where $a_{1}$ and $b_{1}$ are two constants independent of the temperature.

We observed that $\mathrm{w}_{1}$ is closed to 1 for low temperatures and

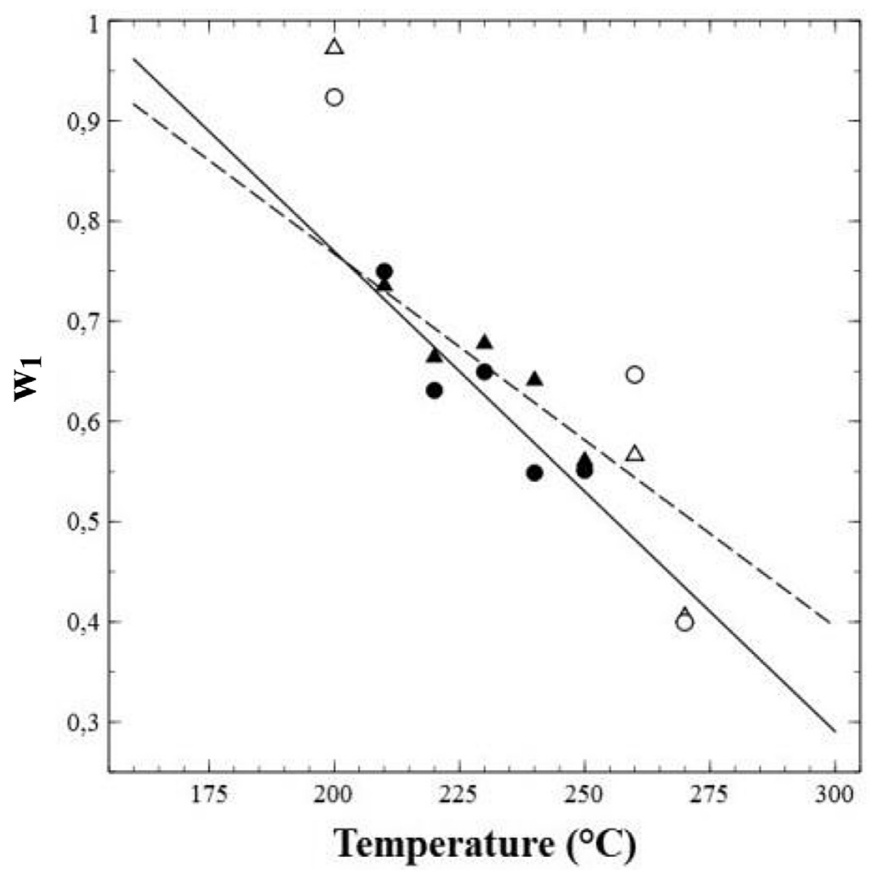

Fig. 9. Weight factor of the primary crystallization vs temperature for isothermal crystallization from the melt $(\bullet)$ and cold crystallization $(\boldsymbol{\Delta})$ with the Hoffman and Lauritzen model fitting with a solid line for crystallization from the melt and dashed line for cold crystallization. Unfilled markers have not been taken into account for the fitting. then decreases to values lower than 0.5 for temperatures above $260{ }^{\circ} \mathrm{C}$. This shows that the formation of the secondary crystallization is promoted for low degree of supercooling. This observation has also been reported by few authors $[18,39]$ with the increase of a first endothermic peak which occurs $10{ }^{\circ} \mathrm{C}$ above the annealing temperature attributed to the melting of the secondary crystallization. In fact, for high annealing temperatures, the diffusion process is very important with a high mobility of the chains allowing the enhancement of the crystalline phase by the growth of a second crystalline structure within lamellae.

\subsection{Induction time modeling}

The crystallization induction time due to nucleation initiation has to be considered in terms of processing time and thus in crystallization models. Following the general approach reported in literature for nucleation and crystallization growth [34,35] and other works $[21,30]$, the temperature dependence of the induction time $\left(t_{i}\right)$ is the same as the one of lamellae growth and therefore follows the Hoffman and Lauritzen model:

$\left.t_{i}(T)=K_{t 0} \exp \frac{E_{t 2}}{R\left(T-T_{g}\right)}\right) \exp \left(\frac{E_{t 1}}{R\left(T_{m 0}-T\right)}\right)$

where $E_{t 1}$ and $E_{t 2}$ are the activation energies for nucleation respectively below the equilibrium melting temperature $T_{\mathrm{m} 0}$ and above the glass transition temperature $T_{g}$.

The induction time $\left(t_{i}\right)$ measured as reported in Fig. 5 has been plotted in Fig. 10 and fitted with Equation (11) for crystallization from the melt and cold crystallization. Activation energy values $E_{t 1}$ and $\mathrm{E}_{\mathrm{t} 2}$ range between 2.5 and $4.8 \mathrm{~kJ} \mathrm{~mol}^{-1}$ are low and consistent with literature $[21,30]$. Contrary to later modeling, induction times measured at $200{ }^{\circ} \mathrm{C}, 260{ }^{\circ} \mathrm{C}$ and $270{ }^{\circ} \mathrm{C}$ have been taken into account to fit the model because they depend only on the beginning of the crystallization. The induction time at $270{ }^{\circ} \mathrm{C}$ is about $9 \mathrm{~min}$

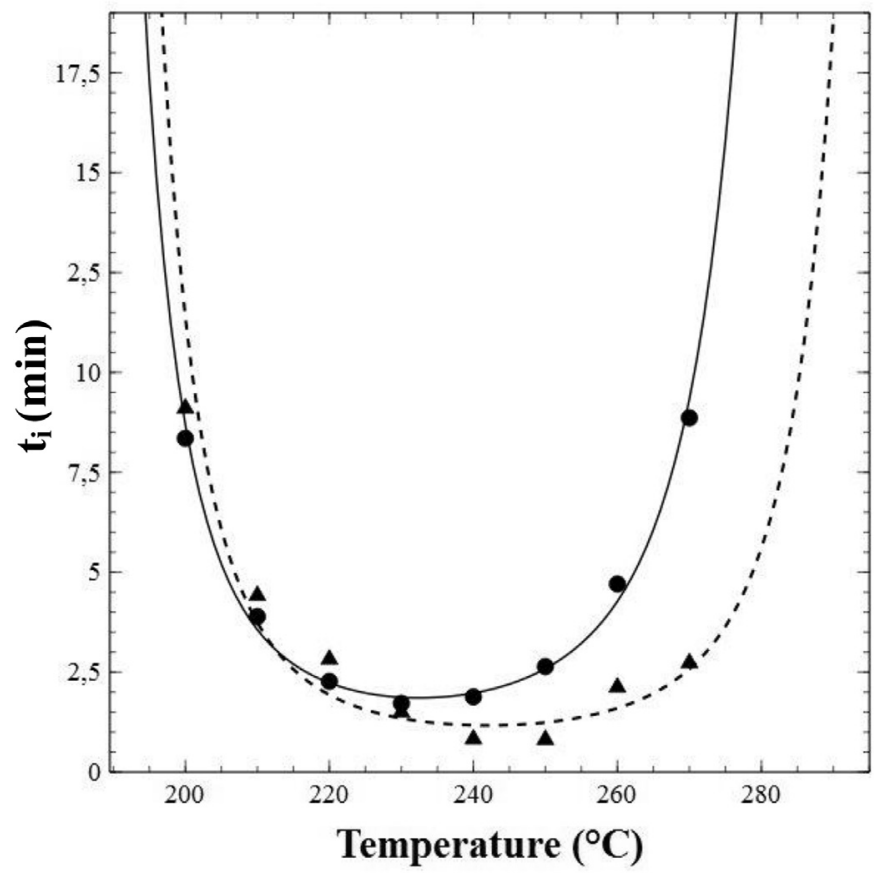

Fig. 10. Induction time vs temperature for isothermal crystallization from the melt and cold crystallization ( $\boldsymbol{\Delta}$ ) with the Hoffman and Lauritzen model fitting with a solid line for crystallization from the melt and dashed line for cold crystallization. 
which is consistent with the crystallization initiation time measured with the microscopic study in Fig. 4. It has been observed that for temperatures closed to the $T_{g}$, induction times for crystallization from the melt and cold crystallization are similar whereas for temperatures near $\mathrm{T}_{\mathrm{m}}$, the induction time of cold crystallization is lower than crystallization from the melt. This has been explained by the formation of nuclei during the heating from the glassy state to the annealing temperature for cold crystallization. For annealing temperatures closed to $T_{g}$, the nucleation mechanism is very fast thus no difference has been observed for induction time for both crystallization.

\subsection{Overall crystallization kinetic modeling}

From modeling of kinetic constants $\left(\mathrm{K}_{1}\right.$ and $\left.\mathrm{K}_{2}\right)$, weight factors $\left(\mathrm{w}_{1}\right.$ and $\mathrm{w}_{2}$ ) and induction times $\left(\mathrm{t}_{\mathrm{i}}\right)$ depending on temperature, the evolution of the relative crystallinity depending on time can be plotted with the modified Hillier model (Equation (4)) for the overall crystallization process as well as for the separated primary and secondary crystallizations. Fig. 11 shows the plot of the modified Hillier model compared to experiments for the overall crystallization, the primary and secondary crystallizations at $210{ }^{\circ} \mathrm{C}$, $230{ }^{\circ} \mathrm{C}$ and $250^{\circ} \mathrm{C}$ for crystallization from the melt. At the beginning of the crystallization, the curves of overall crystallization and primary crystallization are confounded which shows that the secondary crystallization is negligible during the early stage of crystallization. Then, the secondary crystallization occurs with a lower crystallization kinetics corresponding to the enhancement of the first crystallization with the growth of a second crystalline structure within lamellae. As it was observed for the crystallization weight factor, the proportion of the secondary crystallization process increases with the annealing temperature which shows that this mechanism is facilitated for high temperatures corresponding to high diffusion mechanisms.

As the relative crystallinity of PEKK 60/40 depending on time can be determined for any temperatures with the modified Hillier model, TTT diagrams of the relative volume fraction crystallinity for the overall crystallization (Fig. 12a) and also for the separated primary (Fig. 12b) and secondary crystallization (Fig. 12c) have been built allowing the determination of the crystallinity of the material for any isothermal crystallization process as well as corresponding crystallinity ratios of each crystallization mechanism. As expected, crystallization kinetics are the most important for temperatures around $230{ }^{\circ} \mathrm{C}$ and become very slow close to the glass transition and the melting temperature. For instance, Fig. 12a shows that around $230{ }^{\circ} \mathrm{C}$, it takes approximatively $25 \mathrm{~min}$ to reach $95 \%$ of the relative crystallinity whereas the last $5 \%$ takes more than 45 min to be done. This is consistent with the fact that the first crystallization mechanism is fast compared to the secondary crystallization. As it was shown previously, the secondary crystallization process is promoted for high annealing temperatures (Fig. 12c) which is the opposite for the primary crystallization (Fig. 12b).

\section{Conclusion}

Isothermal crystallization kinetics of PEKK 60/40 for crystallization from the melt and cold crystallization were characterized by using a DSC. It was observed a crystallization induction time related to nucleation initiation delaying the crystallization process due to the low crystallization kinetics of PEKK 60/40. This induction time was modeled with a Hoffman and Lauritzen and taken into account in the crystallization kinetics modeling. It was observed lower induction times for cold crystallization at low degree of supercooling probably induced by the formation of nuclei during the heating from the glassy state to the annealing temperature. Isothermal
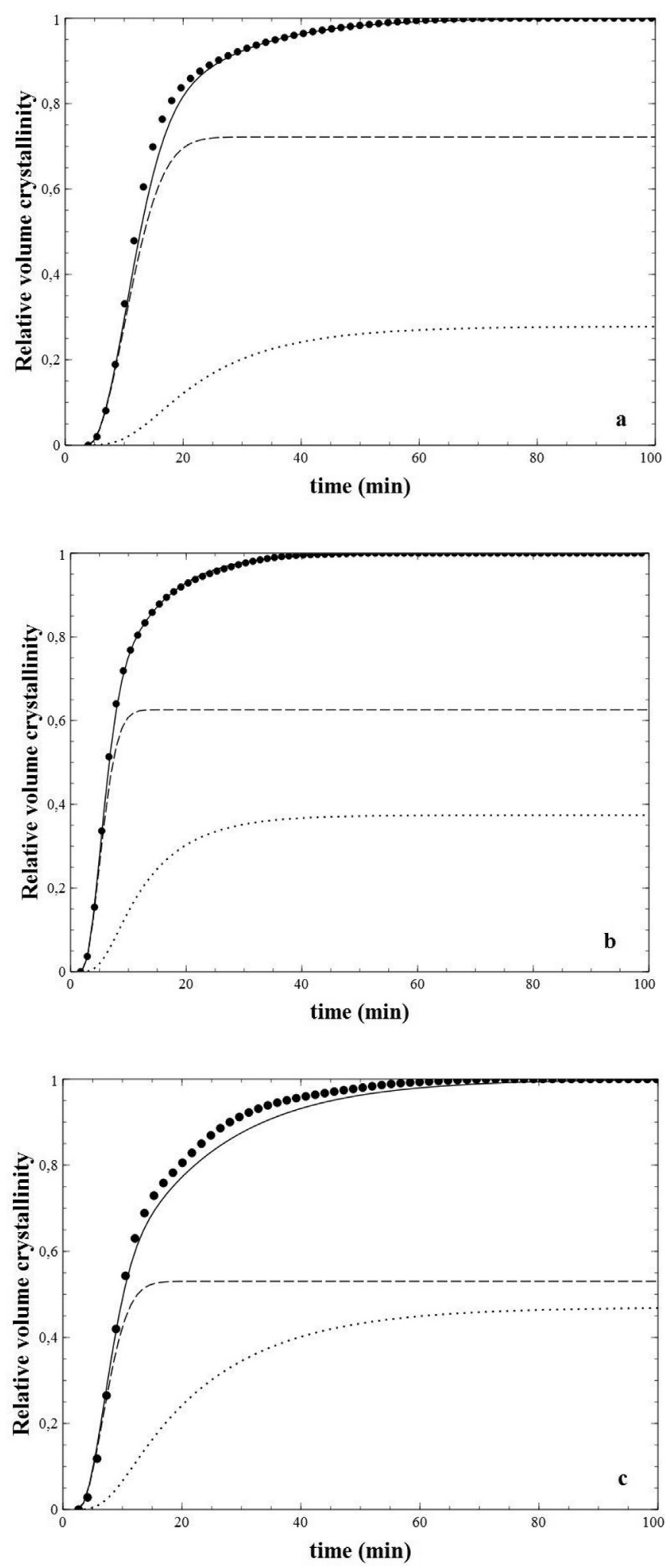

Fig. 11. Relative volume fraction crystallinity $\alpha(\mathrm{t})$ vs time $(\bullet)$ with the Hillier model for the overall crystallization (solid curves), the primary crystallization (dashed curves) and the secondary crystallization (dotted curves) at $210^{\circ} \mathrm{C}$ (a), $230{ }^{\circ} \mathrm{C}$ (b) and $250{ }^{\circ} \mathrm{C}$ (c) for crystallization from the melt.

crystallization kinetics of PEKK 60/40 were modeled with a modified Hillier model related to the growth of a first crystallization mechanism followed by a slower secondary process attributed to 

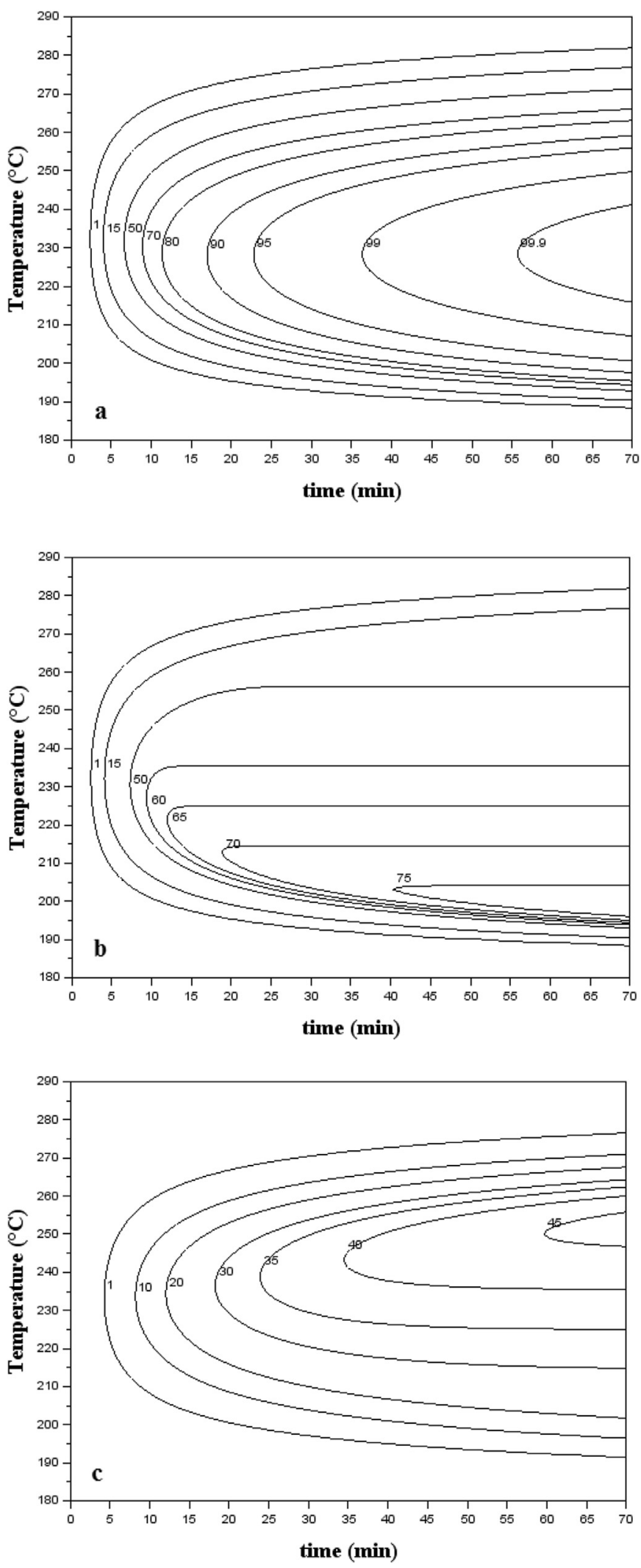

Fig. 12. TTT diagram of the relative volume fraction crystallinity for the overall crystallization (a), the primary crystallization (b) and the secondary crystallization (c) for crystallization from the melt.

the enhancement of the crystalline structure with the growth of a second crystalline structure within lamellae. From the fitting of the
Hillier model with isothermal crystallization experiments, the Avrami exponent of the first crystallization mechanism was found to be equal to 2 related to a two dimensional growth with an instantaneous nucleation confirmed by microscopic observations whereas the Avrami exponent of the secondary crystallization was found to be equal to 1 related to a one dimensional growth with an instantaneous nucleation. Primary and secondary crystallizations rate of the modified Hillier model were modeled by the Hoffman and Lauritzen growth equation showing a very fast crystallization kinetics around $230{ }^{\circ} \mathrm{C}$. Cold crystallization process seems to be faster than melt crystallization due to a lower final degree of crystallinity. According to the linear modeling of the primary crystallization weight factor, the secondary mechanism was found to be enhanced for low degree of supercoolings due to a high diffusion process. Thanks to a full modeling of crystallization kinetics, TTT diagrams of the relative volume fraction crystallinity of PEKK 60/40 for the overall crystallization and also for the corresponding primary and secondary crystallization mechanisms have been plotted providing a useful tool for PEKK 60/40 processing.

\section{Acknowledgments}

The authors wish to thank Arkema company for providing PEKK materials and Vincent Michel from PIMM laboratory for the WAXS measurements.

\section{References}

[1] P.C. Dawson, D.J. Blundell, X-ray data for poly(aryl ether ketones), Polymer 21 (1980) 577-578, http://dx.doi.org/10.1016/0032-3861(80)90228-1.

[2] D.J. Blundell, B.N. Osborn, The morphology of poly(aryl-ether-ether-ketone), Polymer 24 (1983) 953-958, http://dx.doi.org/10.1016/0032-3861(83)901441.

[3] J.N. Hay, D.J. Kemmish, J.I. Langford, A.I.M. Rae, The structure of crystalline PEEK, Polym. Commun. 25 (1984) 175-178.

[4] P. Cebe, S.-D. Hong, Crystallization behaviour of poly(ether-ether-ketone), Polymer 27 (1986) 1183-1192, http://dx.doi.org/10.1016/0032-3861(86) 90006-6.

[5] C.N. Velisaris, J.C. Seferis, Crystallization kinetics of polyetheretherketone (peek) matrices, Polym. Eng. Sci. 26 (1986) 1574-1581, http://dx.doi.org/ 10.1002/pen.760262208.

[6] S. Kumar, D.P. Anderson, W.W. Adams, Crystallization and morphology of poly(aryl-ether-ether-ketone), Polymer 27 (1986) 329-336, http://dx.doi.org/ 10.1016/0032-3861(86)90145-X.

[7] Y. Seo, S. Kim, Nonisothermal crystallization behavior of poly(aryl ether ether ketone), Polym. Eng. Sci. 41 (2001) 940-945, http://dx.doi.org/10.1002/ pen.10793.

[8] L. Jin, J. Ball, T. Bremner, H.-J. Sue, Crystallization behavior and morphological characterization of poly(ether ether ketone), Polymer 55 (2014) 5255-5265, http://dx.doi.org/10.1016/j.polymer.2014.08.045.

[9] K.H. Gardner, B.S. Hsiao, R.R. Matheson, B.A. Wood, Structure, crystallization and morphology of poly (aryl ether ketone ketone), Polymer 33 (1992) 2483-2495, http://dx.doi.org/10.1016/0032-3861(92)91128-0.

[10] S.Z.D. Cheng, R.-M. Ho, B.S. Hsiao, K.H. Gardner, Polymorphism and crystal structure identification in poly(aryl ether ketone ketone)s, Macromol. Chem. Phys. 197 (1996) 185-213, http://dx.doi.org/10.1002/macp.1996.021970115.

[11] R.-M. Ho, S.Z.D. Cheng, B.S. Hsiao, K.H. Gardner, Crystal morphology and phase identification in poly(aryl ether ketone)s and their copolymers. 3. Polymorphism in a polymer containing alternated terephthalic acid and isophthalic acid isomers, Macromolecules 28 (1995) 1938-1945, http:// dx.doi.org/10.1021/ma00110a030.

[12] B.S. Hsiao, I.Y. Chang, B.B. Sauer, Isothermal crystallization kinetics of poly(ether ketone ketone) and its carbon-fibre-reinforced composites, Polymer 32 (1991) 2799-2805, http://dx.doi.org/10.1016/0032-3861(91)90111-U.

[13] D.J. Blundell, A.B. Newton, Variations in the crystal lattice of PEEK and related para-substituted aromatic polymers: 2. Effect of sequence and proportion of ether and ketone links, Polymer 32 (1991) 308-313, http://dx.doi.org/ 10.1016/0032-3861(91)90019-F.

[14] R.K. Krishnaswamy, D.S. Kalika, Glass transition characteristics of poly(aryl ether ketone ketone) and its copolymers, Polymer 37 (1996) 1915-1923, http://dx.doi.org/10.1016/0032-3861(96)87309-5.

[15] M. Hojjati, J. Chen, A. Yousefpour, J. Pratte, in: Crystallization Kinetics of CypekTM Poly Ether Ketone Ketone, 2008.

[16] S. Dominguez, Relation structure/propriétés de polymères et mélanges thermoplastiques thermostables - Applications Aéronautiques Hautes Températures, Pau, 2013. http://www.theses.fr/2013PAUU3031 (accessed 
February 17, 2015).

[17] J. Guenther, M. Wong H.-J. Sue, T. Bremner, J. Blümel, High-temperature steam-treatment of PBI, PEKK, and a PEKK-PBI Blend: a solid-state NMR and IR spectroscopic study, J. Appl. Polym. Sci. 128 (2013) 4395-4404, http:// dx.doi.org/10.1002/app.38695.

[18] L. Quiroga Cortés, N. Caussé, E. Dantras, A. Lonjon, C. Lacabanne, Morphology and dynamical mechanical properties of poly ether ketone ketone (PEKK) with meta phenyl links, J. Appl. Polym. Sci. 133 (19) (2016), http://dx.doi.org/ 10.1002 /app.43396.

[19] S.Z.D. Cheng, M.Y. Cao, B. Wunderlich, Glass transition and melting behavior of poly(oxy-1,4-phenyleneoxy-1,4-phenylenecarbonyl-1,4-phenylene) (PEEK), Macromolecules 19 (1986) 1868-1876, http://dx.doi.org/10.1021/ ma00161a015.

[20] P.J. Holdsworth, A. Turner-Jones, The melting behaviour of heat crystallized poly(ethylene terephthalate), Polymer 12 (1971) 195-208, http://dx.doi.org/ 10.1016/0032-3861(71)90045-0.

[21] O. Verhoyen, F. Dupret, R. Legras, Isothermal and non-isothermal crystallization kinetics of polyethylene terephthalate: mathematical modeling and experimental measurement, Polym. Eng. Sci. 38 (1998) 1594-1610, http:// dx.doi.org/10.1002/pen.10330.

[22] X.F. Lu, J.N. Hay, Isothermal crystallization kinetics and melting behaviour of poly(ethylene terephthalate), Polymer 42 (2001) 9423-9431, http:// dx.doi.org/10.1016/S0032-3861(01)00502-X.

[23] I.H. Hillier, Modified avrami equation for the bulk crystallization kinetics of spherulitic polymers, J. Polym. Sci. A 3 (1965) 3067-3078, http://dx.doi.org/ 10.1002/pol.1965.100030902.

[24] M. Avrami, Kinetics of phase change. I general theory, J. Chem. Phys. 7 (1939) 1103-1112, http://dx.doi.org/10.1063/1.1750380.

[25] D.J. Blundell, V. Bayon, The crystal structure of poly(ether ketone) copolymers, Polymer 34 (1993) 1354-1360, http://dx.doi.org/10.1016/0032-3861(93) 90845-2.

[26] B.S. Hsiao, K.H. Gardner, S.Z.D. Cheng, Crystallization of poly(aryl ether ketone ketone) copolymers containing terephthalate/isophthalate moieties, J. Polym. Sci. Part B Polym. Phys. 32 (1994) 2585-2594, http://dx.doi.org/10.1002/ polb.1994.090321604.

[27] K.H. Gardner, B.S. Hsiao, K.L. Faron, Polymorphism in poly(aryl ether ketone)s, Polymer 35 (1994) 2290-2295, http://dx.doi.org/10.1016/0032-3861(94)
90763-3.

28] B.S. Hsiao, R.-M. Ho, S.Z.D. Cheng, Time-resolved synchrotron X-ray study of crystalline phase transition in poly(aryl ether ketone ketone) containing alternated terephthalic/isophthalic moieties, J. Polym. Sci. Part B Polym. Phys 33 (1995) 2439-2447, http://dx.doi.org/10.1002/polb.1995.090331715.

[29] I. Coccorullo, R. Pantani, G. Titomanlio, Crystallization kinetics and solidified structure in iPP under high cooling rates, Polymer 44 (2003) 307-318, http:// dx.doi.org/10.1016/S0032-3861(02)00762-0.

[30] J.M. Kenny, A. Maffezzoli, L. Nicolais, A new kinetic model for polymer crystallization derived by calorimetric analysis, Thermochim. Acta. 227 (1993) 83-95, http://dx.doi.org/10.1016/0040-6031(93)80252-6.

[31] B. Wunderlich, Macromolecular Physics, Elsevier, 2012.

[32] W. Banks, A. Sharples, The AVRAMI equation in polymer crystallization, Makromol. Chem. 59 (1963) 233-236, http://dx.doi.org/10.1002/ macp.1963.020590119.

33] W. Banks, A. Sharples, J.N. Hay, The effect of simultaneously occurring processes on the course of polymer crystallization, J. Polym. Sci. A 2 (1964) 4059-4067, http://dx.doi.org/10.1002/pol.1964.100020923.

34] D. Turnbull, J.C. Fisher, Rate of nucleation in condensed systems, J. Chem. Phys. 17 (1949) 71-73, http://dx.doi.org/10.1063/1.1747055.

[35] J.D. Hoffman, J.I. Lauritzen, Crystallization of bulk polymers with chain folding: theory of growth of lamellar spherulites, J. Res. Natl. Bur. Stand. Sect. Phys. Chem. 65A (1961) 297, http://dx.doi.org/10.6028/jres.065A.035.

[36] J.D. Hoffman, R.L. Miller, Kinetic of crystallization from the melt and chain folding in polyethylene fractions revisited: theory and experiment, Polymer 38 (1997) 3151-3212, http://dx.doi.org/10.1016/S0032-3861(97)00071-2.

[37] T. Liu, Z. Mo, S. Wang, H. Zhang, Isothermal melt and cold crystallization kinetics of poly(aryl ether ether ketone ketone) (PEEKK), Eur. Polym. J. 33 (1997) 1405-1414, http://dx.doi.org/10.1016/S0014-3057(97)00016-5.

38] M.J. Jenkins, J.N. Hay, N.J. Terrill, Structure evolution in melt crystallised PEEK, Polymer 44 (2003) 6781-6787, http://dx.doi.org/10.1016/S0032-3861(03 00749-3.

[39] M. Dasriaux, S. Castagnet, L. Thilly, L. Chocinski-Arnault, S.A.E. Boyer, Evolution of the amorphous fraction of PEEK during annealing at atmospheric and high pressure above the glass transition temperature, J. Appl. Polym. Sci. 130 (2013) 1148-1157, http://dx.doi.org/10.1002/app.39297. 